\title{
Automated Hand Washing System With Hand Dryer
}

\author{
Jolan B. Sy ${ }^{1}$, Wubishet Degife ${ }^{2}$,Wondetir Teka ${ }^{3}$, Edward B. Panganiban ${ }^{4}$ \\ ${ }^{1,3}$ School of Electrical and Computer Engineering, Kombolcha Institute of Technology, \\ Wollo University, Ethiopia \\ ${ }^{2}$ School of Mechanical and Chemical Engineering, Kombolcha Institute of Technology, \\ Wollo University, Ethiopia \\ ${ }^{4}$ Isabela State University, Echague, Isabela, Philippines
}

\begin{abstract}
There is an urgent need to combat COVID 19 and to find strategies to minimize the devastating effect that causes in the community. This paper focuses on an automated handwashing system with a dryer that could be deployed in public or private areas. The system uses a single Arduino UNO, ultrasonic sensor, hand dryer( fan blower with heating element), relay, motor pump for Water and Soap, Containers for soap and water, and the frame of the system. An important feature designed into the system is the essentially independent operation of the two systems, which hand dryer and hand wash despite being controlled from a common micro-controller. The system encourages the user to observe the proper WHO protocol in handwashing through a sequence of water-soap-water delivery. Appropriate amounts of soap and water are delivered within allotted times, and time gaps between soap and water deliveries. The hot dryer used to dry the wash hands to make sure that all bacteria will be removed. The no-contact system decreases the possible viral transmission of any virus. Proteus is used to test its functionality and responses based on the requirement of the system. A prototype is then built to test and verify the system's actual operation and responses. Tests show that all the requirements are met. It follows perfectly the required hand wash protocol from the WHO and drying of hands. The paper shows photos of the built and tested prototype, a diagram of the initial system design concept, a screen capture of the control system software model, a schematic diagram of the control system, a sketch with dimensions of the handwashing machine frame or housing, and the flowchart on which the Arduino script is developed. The operation and user-interaction of the actual system are also described.
\end{abstract}

Key words: Handwashing system, Dryer, COVID-19, Proteus, Arduino UNO

\section{INTRODUCTION}

The relevance of hand washing cannot be downplayed, particularly in improving countries where it is common practice to eat with hands. In some emerging societies, there is often a hesitation to wash hands before meals; and in some, hand washing has established a generally common practice. Wanting to eat with your hands has been continuing for decades before anyone suddenly learned of washing their hands. So, along the way, through technologies and hygiene measures, individuals are taught to improve handwashing. Hand washing is the perhaps most effective way to avoid the transmission of diseases. Not washed or badly clean hands are very popular forms to transmit many infections such as fever, colds, diarrhea, sore throat, and other hand-borne diseases.

Hand Hygiene is one of the most effective strategies to mitigate the transmission of pathogens and avoid outbreaks, such as the virus COVID-19. Community members will provide a vital role in the battle against COVID-19 by implementing regular hand hygiene as a component of their daily activity.[1] Promoting the practice of handwashing with soap and water is one of the simplest, low tech and most cost-effective public health measures to prevent transmission of COVID 19 as well as many other communicable diseases[2]. The COVID- 19 outbreak has given renewed attention to the failure of community preparation and its effect on urban health in emerging nations [3]. Soap must be used in association with flowing water in handwashing is a primary method to avoid the transfer of COVID-19 [4] [5] [6]. In this health practice, it will fight COVID-19 and will help individuals associated with health risks [7] and those of the children [8]. In fact, this is an important method of infection control [9] or limiting the spread of this pandemic [10].

Better soap-washing percentages on key public health instances have been shown to be very reliable [11]. The availability of handwashing stations is perceived to be a simple personal hygiene activity with a positive externality in terms of public health benefits. Its access also depends on the availability of a secure supply of a sufficient quantity of water and reasonable rates. From the study of Jolan Baccay Sy and his friends, they stated that multi-station automatic hand wash provides complete and hygienic hand washing activities with soap and water through its several stations that apparently and essentially operate independently of each other, satisfy the WHO handwashing duration standard and accommodate the WHO handwashing technique [12]. 
Because of the COVID-19 pandemic, there are several handwashing technologies have evolved. A handwashing station was designed for infrastructure-restricted areas in Bangladesh was developed. Their projects included the integration of behavioral models for water, sanitation, and hygiene intervention [13]. Automated handwashing that helps individuals not only with regular people but people with dementia using video and a process called observable Markov decision was made by Hoey et al. [14]. Another innovation was developed by Li et al. called WristWatch. This is a wrist-worn detection interface that combines a Hidden Markov Model analysis tool and an inertial calculation unit that allows automatic evaluation of handwashing habits [15]. Emotional intelligence was associated with an assistive handwashing system was also established in a thesis conducted by Lin [16]. Health workers' handwashing was also observed in hospitals to make sure that diseases will not be transmitted. Hence, Naim et al. developed stain detection in automatic handwashing by applying an audit vision system [17].

Automatic handwashing has many benefits, such as hygiene, lower costs, and minimal waste generation [18]. Through all those reviewed documents, this paper conceptualized a project that will automatically wash hands and be integrated with a hand dryer. The researchers came up with a design that will reduce the risk of transfer of disease, solve the challenges experience related to washing and drying of hands. This will also improve the level of hygiene of individuals and also the awareness of people that there are designs like this. The methods used were explained in the next discussion.

\section{METHODOLOGY}

The development of this project used different methodologies, design, modeling, simulation, hardware manufacturing, testing, and data collection.

\subsection{System requirements}

Keeping hands clean is one of the most important to avoid getting sick and spreading germs to others, especially in this pandemic time since Many diseases are spread by not washing hands with soap and clean water properly. The system requirement was based on the World Health Organization (WHO) protocol requires that hand washing should be done for a duration of 20 seconds, and it will be dry.

\subsection{Control System Design}

Control System Design is illustrated in figure 1.

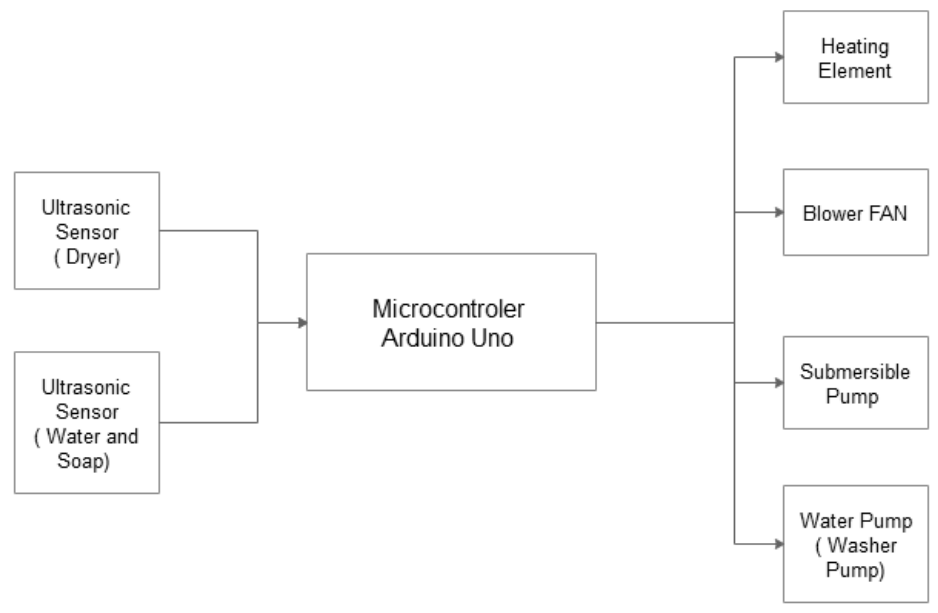

Figure 1: Automated Handwashing System with Hand Dryer's Block Diagram

There are two ultrasonic sensors. The first sensor is used for hand wash and the other used for a hand dryer. The ultrasonic is used and work by emitting sound waves, and the researcher chooses the ultrasonic sensor since it works at any time of the day, either outdoor or indoor. The heating element and blower fan was assembled as a hand dryer. The two pumps, which are the submersible pump and the centrifugal pump, is used in water and soap containers.

\subsection{Software Modeling and Simulation}

Proteus software is used to design the Automated Handwashing System with Hand Dryer's control system is shown in Fig. 2.

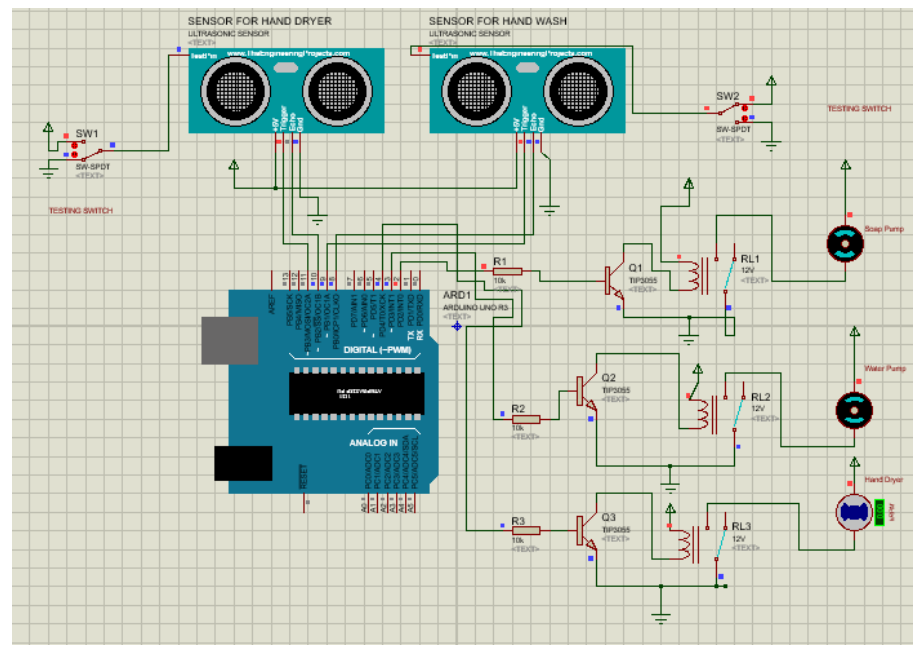

Figure 2: Automated Handwashing System with Hand Dryer's Control System Software Simulation Model 
Jolan B. Sy et al., International Journal of Emerging Trends in Engineering Research, 8(9), September 2020, 6068 - 6073

Simulation Model Parts List:

1 - Arduino Uno

2 - Ultrasonic sensors (HC SR-04)

2- Simple DC motor model

$1-12-\mathrm{V}$ DC voltage source

$1-5-\mathrm{V}$ DC voltage source

3- Relay ( 12 Volts)

1-Blower Fan

1- Heating Element

Arduino UNO [19]-[26] is a type of microcontroller that is based on the concept of a Microchip ATmega328P microcontroller that controls the input or output of the smart irrigation system. Ultrasonic sensor is an electronic component that can determine the distance to an item by using a sound wave. It calculates distance by sending a sound wave to a particular frequency and by listening to the sound wave rebounding. Simple DC motor was also used in this project. It uses two voltage sources both $\mathrm{DC}$ with $5 \mathrm{~V}$ and $12 \mathrm{~V}$ output. Other important components utilized were $12 \mathrm{~V}$ relay, blower fan and heating element.

\section{Flowchart}
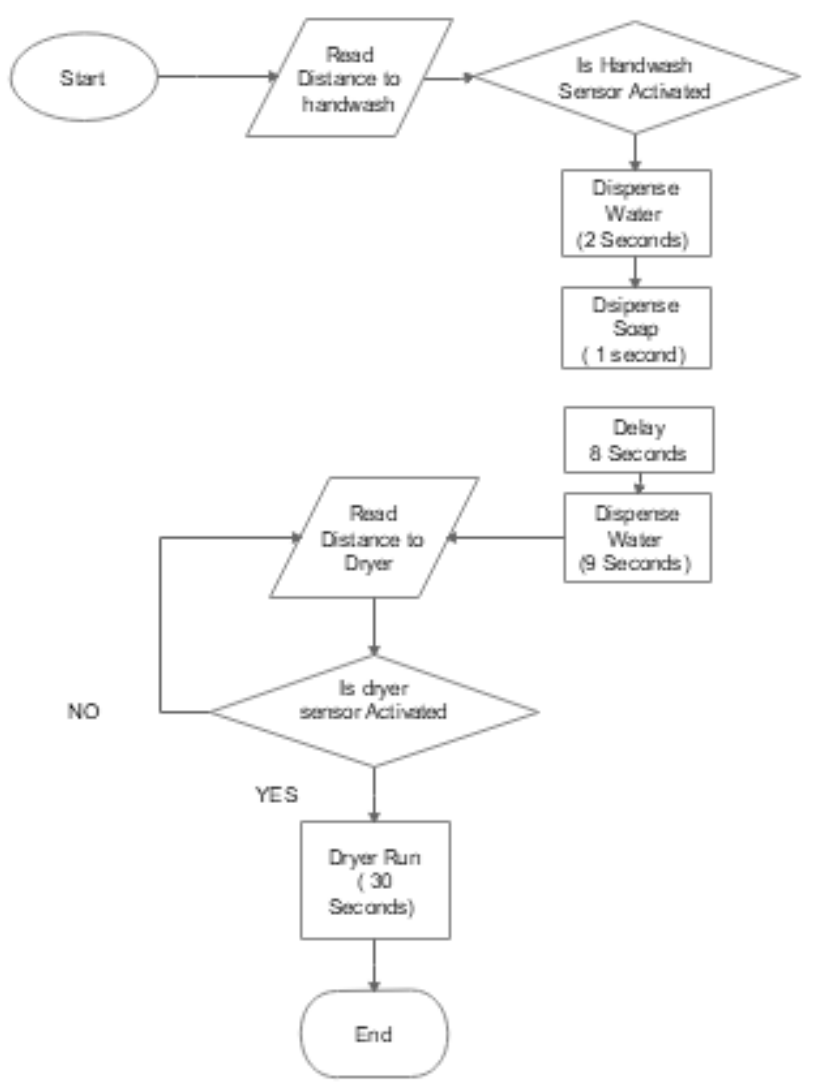

Figure 3: Automated Handwashing System with Hand Dryer's Flow Chart

\subsection{Automated Handwashing System with Hand Dryer's Hardware Prototype Development}

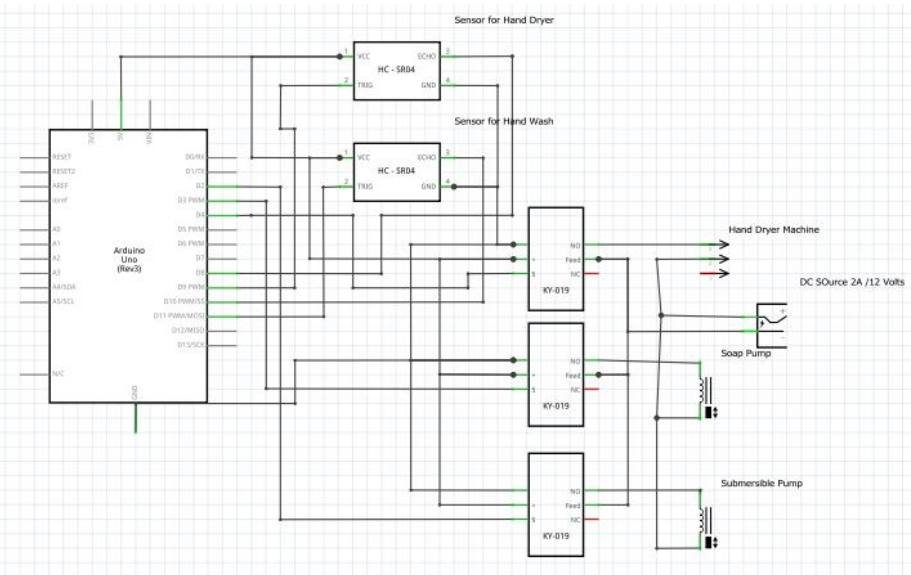

Figure 4: Automated Handwashing System with Hand Dryer's Schematic Diagram

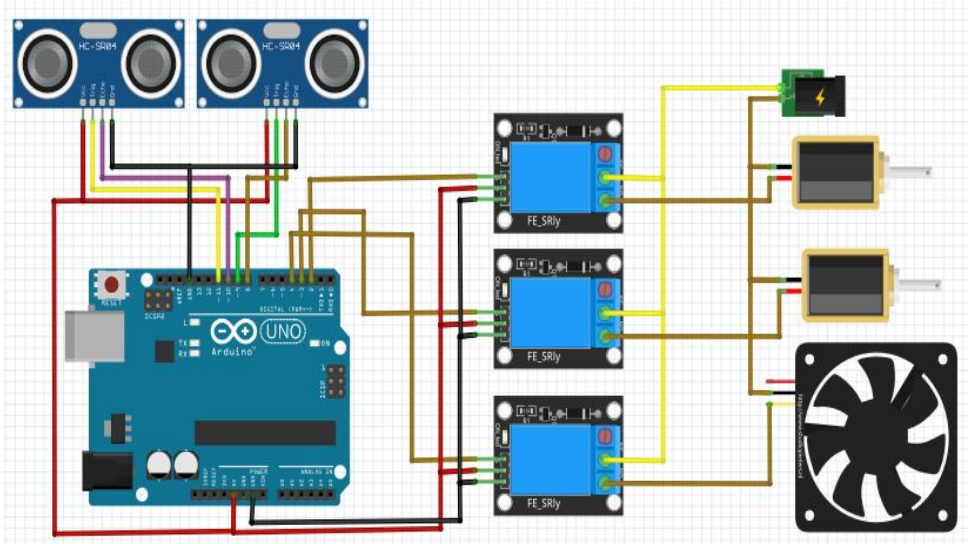

Figure 5: Automated Handwashing System with Hand Dryer's Pictorial Circuit Diagram

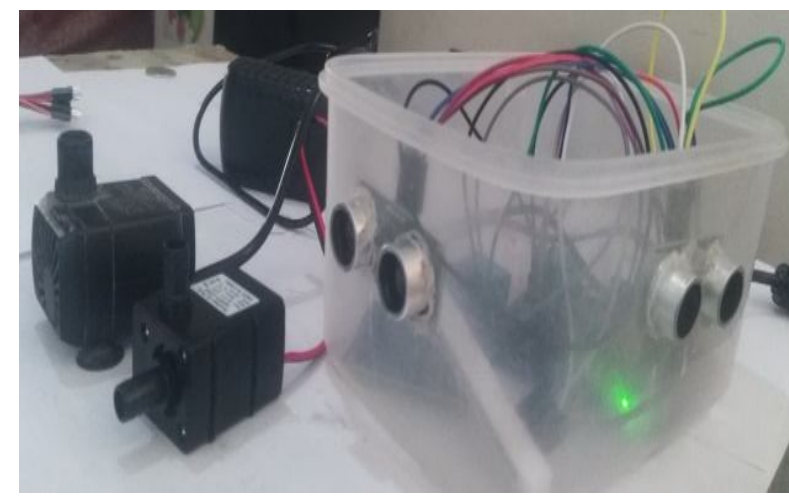

Figure 6: Automated Handwashing System front View 
Jolan B. Sy et al., International Journal of Emerging Trends in Engineering Research, 8(9), September 2020, 6068 - 6073

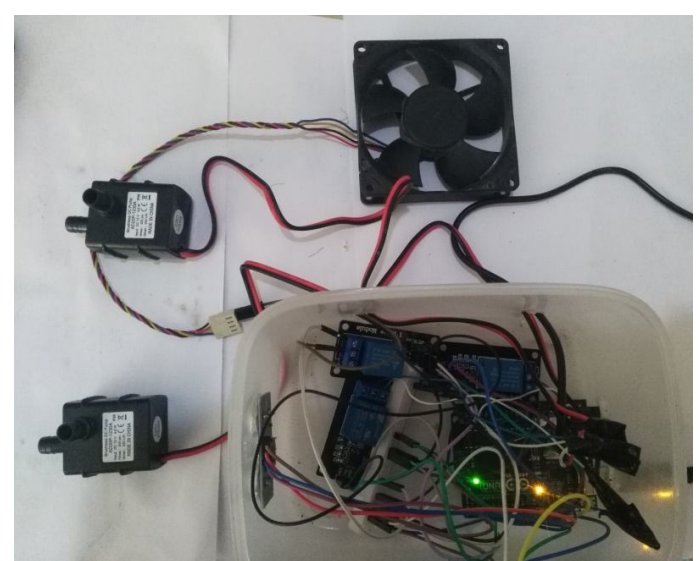

Figure 7: Automated Handwashing System with Hand Dryer's Prototype Hardware

\subsection{System Tests and Data Collection}

Throughout the number of iterations undertaken in the development of this project, from its control system software model through its final hardware prototype, a series of similar tests are conducted.

1. Sensor for Hand wash- Test the sensor time and delay with respect to the host length from the container.

2. Sensor for Dyer- Test the sensor time and delay with respect to the heating element.

3. Submersible Pump - Test the flow and amount of water if it dispenses.

4. Power Supply- Test the load requirements of Arduino and other components.

\section{RESULTS AND DISCUSSION}

\subsection{Hand Washing Instructions}

Washing your hands is simple, and it is among the most successful approaches to decrease the transmission of contagious disease. Clean hands will avoid germs from spreading from one person to another and through the community, from home and work to health care facilities and hospitals.

Follow these five steps every time [27].

1. Wet your hands with clean water and apply soap.

2. Lather your hands by rubbing them together with the soap. Lather the backs of your hands, between your fingers, and under your nails.

3. Scrub your hands for at least 20 seconds.

4. Rinse your hands well under clean, running water.

5. Dry your hands using air hand dry.

\subsection{Results of the tests conducted}

The tests conducted and the results for 1) Control System Software Model Tests, 2) Control System Hardware Model
Tests, and 3) Automated Handwashing System with Hand Dryer's Prototype Tests are all similar.

Table 1: Summary of System Responses Under the Different Test Cases

\begin{tabular}{|l|l|l|l|l|}
\hline \multicolumn{3}{|l|}{ Result/System Response } \\
\hline $\begin{array}{l}\text { Test } \\
\text { Parts }\end{array}$ & Description & $\begin{array}{l}\text { Proteus } \\
\text { Simulatio } \\
\mathrm{n}\end{array}$ & Hardware & Prototype \\
\hline 1 & $\begin{array}{l}\text { User } \\
\text { Approaches } \\
\text { Within 40 cm } \\
\text { in Hand Wash }\end{array}$ & Working & Working & Working \\
\hline 2 & $\begin{array}{l}\text { Time for Soap } \\
\text { Dispensing }\end{array}$ & Working & Working & Working \\
\hline 3 & $\begin{array}{l}\text { Time for Water } \\
\text { Dispensing }\end{array}$ & Working & Working & Working \\
\hline 4 & $\begin{array}{l}\text { User } \\
\text { Approaches } \\
\text { Within 10 cm } \\
\text { in the hand } \\
\text { dryer }\end{array}$ & Working & Working & Working \\
\hline 5 & $\begin{array}{l}\text { Time for Hand } \\
\text { Drying } \\
\text { Dispensing }\end{array}$ & Working & Working & Working \\
\hline
\end{tabular}

Note that the above tests are performed to check the correctness of the Arduino script, as demonstrated by the way any of the stations go through the prescribed wash cycle once activated. Simultaneously, the tests are also undertaken to check the performance of the various hardware components. The tests turned out acceptable or correct results.

\section{CONCLUSION}

Almost every country in the world closed their borders, even advised their citizen to stay at home, and most of the businesses are closed, and the worst effect most people lost their jobs and the unemployment rate increase. Due to the impact on the economy, countries now started to open their borders and businesses. They give advice protocols to follow. The use of non-contact automated hand wash with a hand dryer is one of the best strategies to eliminates or decrease the spread of coronavirus. Tests show that all the requirements are met. It follows perfectly the required handwash protocol from the WHO and drying of hands. Future work may include solar-powered automated hand wash with non-contact temperature reader as most of the time, and there are power interruptions.

\section{REFERENCES}

[1] WHO, "Who Save Lives : Clean Your Hands in the Context of Covid-19," no. May, pp. 19-20, 2020.

[2] A. A. Taddese, B. Dagnew, H. Dagne, and Z. Andualem, "Mother's Handwashing Practices and Health Outcomes of Under-Five Children in 
Jolan B. Sy et al., International Journal of Emerging Trends in Engineering Research, 8(9), September 2020, $6068-6073$

Northwest Ethiopia," Pediatric Health, Medicine and Therapeutics, vol. Volume 11, pp. 101-108, 2020.

[3] A. Patel, "Preventing COVID-19 Amid Public Health and Urban Planning Failures in Slums of Indian Cities," World Medical and Health Policy, pp. $1-8,2020$.

[4] A. K. Amegah, "Improving handwashing habits and household air quality in Africa after COVID-19," The Lancet Global Health, vol. 8, no. 9, pp. e1110-e1111, 2020.

[5] M. Alzyood, D. Jackson, H. Aveyard, and J. Brooke, "COVID-19 reinforces the importance of handwashing," Journal of Clinical Nursing, pp. 1-2, 2020.

[6] C. H. Dawson, J. B. Mackrill, and R. Cain, "Assessing user acceptance towards automated and conventional sink use for hand decontamination using the technology acceptance model," Ergonomics, vol. 60, no. 12, pp. 1621-1633, 2017.

[7] D. Li, A. Sangion, and L. Li, "Evaluating consumer exposure to disinfecting chemicals against coronavirus disease 2019 (COVID-19) and associated health risks," Environment International, vol. 145, pp. 1-12, 2020.

[8] R. L. Jess and C. L. Dozier, "Increasing handwashing in young children: A brief review," Journal of Applied Behavior Analysis, vol. 53, no. 3, pp. 1219-1224, 2020.

[9] M. Haque, "Handwashing in averting infectious diseases: Relevance to COVID-19," Journal of Population Therapeutics and Clinical Pharmacology, vol. 27, no. Special Issues 1, pp. e37-e52, 2020.

[10] H. Bonful, A. Addo-Lartey, J. Aheto, J. Ganle, B. Sarfo, and R. Aryeetey, "Limiting Spread of COVID-19 in Ghana: Compliance audit of selected transportation stations in the Greater Accra region of Ghana," medRxiv, 2020.

[11] J. B. Tidwell et al., "Impact of a teacher-led school handwashing program on children's handwashing with soap at school and home in Bihar, India," PLoS ONE, vol. 15, no. 2, pp. 1-8, 2020.

[12] J. B. Sy, M. G. Rojo, E. R. Calibara, A. V. Comendador, and W. Degife, "Multi-Station Automated Hand Washing System ( MSAHWS )," no. 3, pp. 36-43, 2020.

[13] K. R. S. Hulland et al., "Designing a handwashing station for infrastructure-restricted communities in Bangladesh using the integrated behavioural model for water, sanitation and hygiene interventions (IBM-WASH)," BMC Public Health, pp. 1-12, 2013.

[14] J. Hoey, P. Poupart, A. von Bertoldi, T. Craig, C. Boutilier, and A. Mihailidis, "Automated handwashing assistance for persons with dementia using video and a partially observable Markov decision process," Computer Vision and Image Understanding, vol. 114, no. 5, pp. 503-519, 2010.

[15] H. Li et al., "WristWash: Towards automatic handwashing assessment using a wrist-worn device," in Proceedings - International Symposium on Wearable Computers, ISWC, 2018, pp. 132-139.

[16] L. Lin, "An Assistive Handwashing System with Emotional Intelligence," 2014.

[17] F. Naim, M. A. Romaino, and R. Hamid, "Enhancement on Stain Detection for Automatic Handwashing Audit Vision System," Lectures in Electrical Engineering, vol. 538, pp. 381-389, 2019.

[18] G. A. Ikechukwu, O. O. Clementina, and C. L. Onyebuchi, "Design and Characterization of Automatic Hand Washing and Drying Machine," American Academic \& Scholarly Research Journal, vol. 6, no. 4, pp. 123-134, 2014.

[19] E. B. Panganiban, "Automated hazardous gas detecting robot using wireless sensor networks with GSM-SMS alert and fire control system for households," International Journal of Advanced Trends in Computer Science and Engineering, vol. 8, no. 3, pp. 804-809, 2019.

[20] E. Panganiban, B. B. Abad, and M. Caranguian, "Aluminum can to WiFi trading system with metal can and plastic bottle collector and monitoring system," International Journal of Emerging Trends in Engineering Research, vol. 8, no. 7, pp. 3639-3644, 2020.

[21] E. B. Panganiban and J. C. Dela Cruz, "RFID-Based Vehicle Monitoring System," in HNICEM 2017 9th International Conference on Humanoid, Nanotechnology, Information Technology, Communication and Control, Environment and Management, 2017, pp. 1-6.

[22] E. B. Panganiban et al., "Real-Time Intelligent Healthcare Monitoring and Diagnosis System Through Deep Learning and Segmented Analysis," IFMBE Proceedings, vol. 74, pp. 15-25, 2019.

[23] E. B. Panganiban, "Microcontroller-based Wearable Blood Pressure Monitoring Device with GPS and SMS Feature through Mobile App," International Journal of Emerging Trends in Engineering Research, vol. 7, no. 6, pp. 32-35, 2019.

[24] M. M. Caranguian, B. B. Abad, and E. B. Panganiban, "Tilapia fishpond monitoring system with fishkill prevention," International Journal of Emerging Trends in Engineering Research, vol. 8, no. 7, pp. 3478-3482, 2020.

[25] B. B. Abad, M. M. Caranguian, and E. B. Panganiban, "IoT-based compact-matic drinking water filtration machine," International Journal of Emerging Trends in Engineering Research, vol. 8, no. 7, pp. 3887-3892, 2020.

[26] E. B. Panganiban, "Rainfall Measurement And 
Jolan B. Sy et al., International Journal of Emerging Trends in Engineering Research, 8(9), September 2020, 6068 - 6073

Flood Warning Systems : A Review," International

Journal of Scientific \& Technology Research, vol. 9, no. 03, pp. 244-254, 2020.

[27] C. P. A. of N. Y. State, "OPWDD issues revised staff guidance for managing COVID-19 B . Staffing Health Checks for All Settings," https://www.cpstate.org/opwdd-issues-revised-staff-g uidance-for-managing-covid-19/, 2020. 